\title{
Habitação de Interesse Social como política pública e implementação do Programa 'Minha Casa, Minha Vida' em cidades médias, o caso de Erechim, RS, Brasil
}

\author{
Habitación de Interés Social como política pública e \\ implementación del programa 'Minha Casa, Minha Vida' en \\ ciudades medias, el caso de Erechim, RS, Brasil
}

\section{Social Housing as public policy and the Implementation of the program 'Minha Casa, Minha Vida' in medium-sized cities, the case of Erechim, RS, Brazil}

\author{
Emerson dos Santos Silva \\ emersonssilva@ufrgs.br \\ Universidade Federal do Rio Grande do Sul, UFRGS, Porto Alegre, RS \\ Josiane Andréia Scotton \\ josiane.andreia@ufrgs.br
}

Universidade Federal do Rio Grande do Sul, UFRGS, Porto Alegre, RS

Vanessa Goulart Dorneles

arq.vanessagdorneles@gmail.com

Universidade Federal de Santa Maria, UFSM, Santa Maria, RS

\begin{abstract}
Resumo: Este trabalho apresenta uma breve contextualização das Políticas Públicas recorrentes no Brasil, adotadas como garantia de acesso à moradia, enquanto direito assegurado pela Constituição Federal de 1988. Faz-se também uma análise de como tais Políticas Públicas se refletiram no município de Erechim e avalia-se como o Poder Público Municipal, responsável pela ordenação da ocupação e uso do solo e gestor das Políticas Públicas, de acordo com o Estatuto da Cidade de 2001, tem atuado na regulamentação destas políticas. Através de entrevistas assistemáticas com a equipe técnica do Departamento de Habitação constatou-se que o modelo adotado no município é limitado pela complexidade do problema e a demandas emergentes. Neste estudo, conclui-se que outras medidas poderiam ser adotadas concomitantemente, tais como os mecanismos previstos no Estatuto da Cidade para sanar o déficit para cidades de porte médio, e contribuindo de fato para uma política habitacional e um desenvolvimento mais sustentável.
\end{abstract}

Palavras-chave: Estatuto da Cidade; entrevistas assistemáticas; desenvolvimento social.

Resumen: En el presente artículo presenta una breve contextualización de las recurrentes políticas públicas en Brasil, adoptada como una garantía de acceso a la vivienda, como derecha de la Federal Constitución de 1988. Se hace también un análisis 
de como las Políticas Públicas se refleja en el Municipio de Erechim y se evalúa como la Prefectura, responsable de la Respuesta de la Oficina de Uso y Uso del Derecho y de las Políticas Públicas, de acuerdo con el Estatuto de la Ciudad de 2001, ha actuado en la reglamentación de esas políticas. El estudio se realizó a través de entrevistas no sistemáticas con el personal técnico del Departamento de Vivienda y se comprobó que el modelo adoptado es limitado, debido a la gran complejidad del problema y la demanda emergente. Este estudio concluye que otras medidas podrían tomarse simultáneamente, como los mecanismos previstos en el Estatuto de la Ciudad para remediar el déficit de las ciudades medianas y, de hecho, contribuir a una política de vivienda y desarrollo más sostenible.

Palabras clave: Estatuto de la Ciudad; entrevistas asistemáticas; desarrollo social.

Abstract: This paper presents a brief contextualization of the recurrent Public Policies in Brazil, adopted as a guarantee of access to housing, as a right guaranteed by the Federal Constitution of 1988. The analysis is also made of how these Public Policies were reflected in the Municipality of Erechim, and it is evaluated how the City Hall, responsible for planning the land uses and manager of Public Policies, according to the City Statute of 2001, has acted in the regulation of these policies. The study was performed through non-systematic interviews with the technical staff of the Department of Housing and it was verified that the model adopted in the municipality is limited, due to the great complexity of the problem and the emerging demand. This study concludes that other measures could be taken concurrently, such as the mechanisms provided for in the City Statute to remedy the deficit for medium-sized cities, and in fact contributing to a housing policy and a more sustainable development.

Keywords: housing of social interest; City Statute; non-systematic interviews; social sustainability.

\section{INTRODUÇÃO}

O Brasil vem enfrentando muitos problemas com relação à habitação, principalmente a Habitação de Interesse Social (HIS), considerada como possível solução para o déficit de moradias no país. Infelizmente, por ser ainda um país emergente e com uma demanda habitacional muito elevada, não surgiram Políticas Públicas suficientemente efetivas para suprir tais demandas, principalmente nas regiões metropolitanas (BONDUKI, 1995). Entretanto, ressalta-se que esta demanda habitacional também ocorre em cidades médias e este trabalho está focado, principalmente, em analisar como estas demandas vêm sendo estruturadas no Município de Erechim. 
Figura 1: Mapas de Localização da área urbana de estudos em relação ao Brasil, Rio Grande do Sul e COREDE Norte, respectivamente.
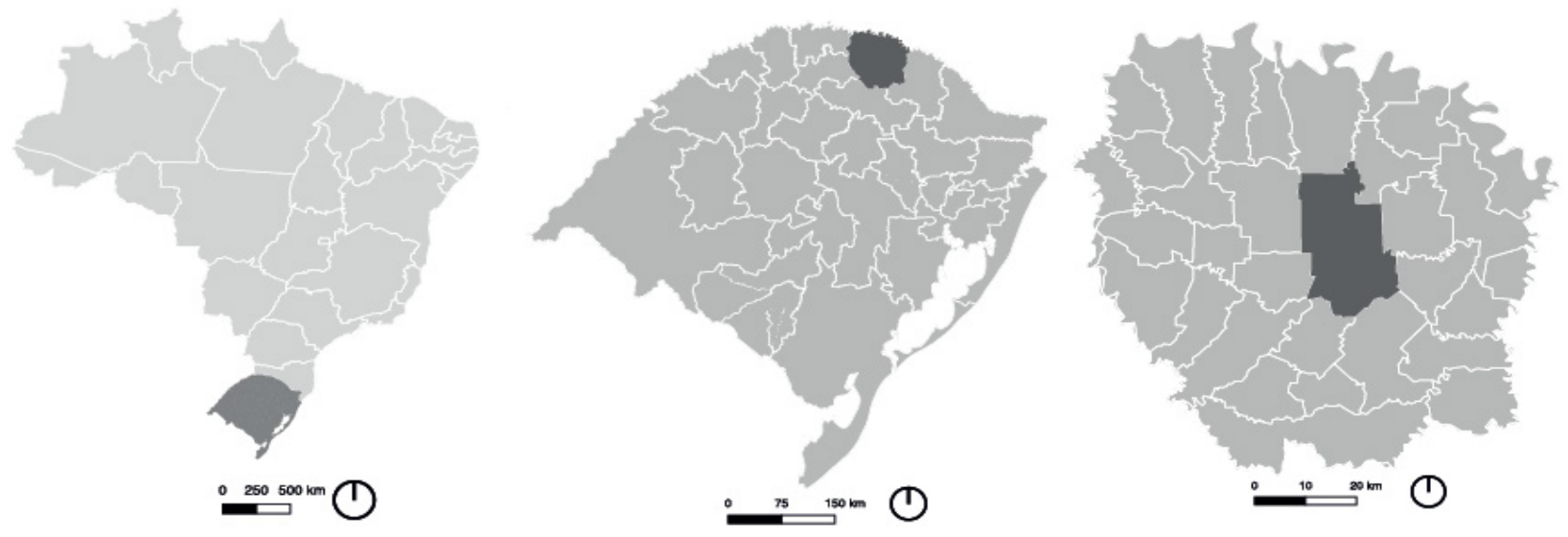

Base cartográfica: IBGE, 2010.

O município de Erechim está situado no sul do Brasil, ao norte do Estado do Rio Grande do Sul, na Microrregião do Alto Uruguai e núcleo do Conselho Regional de Desenvolvimento Norte (COREDE Norte). Segundo o IBGE (2010), a população é de 96.087 hab. com área de 430,669 km² e densidade demográfica de 223,11 hab./ km². O IDHM é considerado bom, de 0,766, e o Produto Interno Bruto (PIB) advém de serviços, indústria e pecuária, respectivamente. Ainda, conforme o IBGE, a cidade não possui assentamentos subnormais e em 2010 foi escolhida para fazer parte do Programa REUNE, que prevê a expansão das universidades federais para cidades fora das regiões metropolitanas. Consolida-se também como uma Capital Sub-regional B, atuando como polo para as cidades na região do Alto Uruguai (IBGE, 2007).

Dada a sua importância regional e suas características físico-sociais, pode-se inferir que a questão da habitação seja crucial para o desenvolvimento urbano deste município, uma vez que sendo uma cidade de porte médio, ainda está em processo de desenvolvimento. Podese, portanto, analisar como a problemática referente ao déficit habitacional em municípios de porte médio pode ser atendida através do planejamento urbano e contribuir para um desenvolvimento urbano mais direcionado às demandas locais. Diante disto, este artigo tem como objetivo analisar a localização das novas unidades habitacionais e verificar a efetividade de sua inclusão dentro da malha urbana.

A análise ocorreu a partir dos processos estabelecidos pela Prefeitura Municipal de Erechim através da Secretaria de Obras Públicas e Habitação, entre os quais destaca-se o de reconhecimento das demandas, a triagem das famílias e possíveis soluções adotadas para resolução do déficit, sem se deter na qualidade arquitetônica e construtiva das edificações. Para isto, parte-se primeiramente do referencial teórico centrado na abordagem da problemática habitacional no Brasil, seguido da metodologia adotada, entrevistas assistemáticas para este estudo de caso e, por fim, destacam-se os resultados obtidos e as considerações finais. 


\section{REFERENCIAL TEÓRICO}

As políticas de habitação no Brasil têm sido falhas em sua essência, pois programas isolados, com objetivos de curto prazo, resumem o histórico de como este déficit foi tratado. Primeiramente, durante o século $X X$, os cortiços e vilas tomaram conta das principais capitais do Brasil, como Rio de Janeiro e São Paulo, os quais mais tarde foram destruídos, pois em geral estas edificações se encontravam em condições insalubres e, devido às leis sanitaristas, muitas delas foram substituídas por novas formas de ocupação (BONDUKI, 1995).

Na sequência, na Era Vargas, surge o debate sobre a habitação ao perceber-se a necessidade de intervenção do Estado, já que a iniciativa privada não teria condições de equacionar o problema da moradia para os trabalhadores. Por conseguinte, algumas medidas são adotadas, como a Lei do Inquilinato e o congelamento dos aluguéis, que acabaram por agravar ainda mais a situação da população de baixa renda, que permanecia sem moradia (BONDUKI, 1995).

Diante desses problemas o auto-empreendimento tornou-se a 'solução' para grande parte da população que prezava tanto pela casa própria como também por não pagar mais aluguel. É possível recordar que além das outras despesas mensais, o aluguel representava grande parte do orçamento que, em muitos casos, se encontrava em condições precárias. Além disto, lembra-se que essa camada da população historicamente não teve acesso aos fundos de financiamento, consequentemente, sem acesso à habitação digna. Diante disso, soluções isoladas não conseguiam mais dar conta deste problema, que se agrava a cada ano, e medidas de cunho legislativo não faltaram para assegurar que a população obtivesse o acesso à moradia.

O fato mais importante a ser recordado é como a Constituição Federal de 1988 trata, especificamente nos artigos 182 e 183, da Política Urbana. Esta regulamenta como deve ocorrer a organização e planejamento das cidades e cita os Planos Diretores como alternativa para a ordenação urbana e sobre os usos e ocupações do solo. A nova Constituição também assegura o acesso à moradia, que deve ser garantido através do Poder Público. Salientase o Artigo 2: "A propriedade urbana cumpre sua função social quando atende às exigências fundamentais de ordenação da cidade expressas no plano diretor" (BRASIL, 1988). Ou seja, a propriedade urbana citada refere-se a terra como parte privada; mas, acima disso, possui uma função social.

Como parte complementar, a promulgação do Estatuto da Cidade - Lei Federal 10.257, de 2001, pretendeu especificar de que forma o Poder Público deveria agir para fazer cumprir a Constituição Federal, atribuindo ao Poder Municipal a gestão da propriedade da terra. Segundo o Estatuto, algumas medidas devem ser tomadas para que a Política Urbana garantida pela Constituição seja implementada, tais como o IPTU Progressivo, a Desapropriação com Pagamentos em Títulos, dentre outros instrumentos necessários para a gestão do solo urbano (HOLANDA, 2011). Trata-se de um importante avanço teórico na expansão do direito à moradia, defendendo os princípios ideários da reforma urbana. Holanda (2011) entende o Estatuto da Cidade em três sentidos: i) instituição de instrumentos 
que visam induzir as formas de uso e ocupação do solo; ii) ampliação das possibilidades de regularização das posses urbanas; iii) gestão democrática enquanto participação direta do cidadão em processos decisórios sobre os destinos da cidade.

Com o objetivo de impedir a especulação e regular o preço da terra através do cumprimento da função social da propriedade, o Estatuto da Cidade permite ao estado ter maior controle sobre uso e ocupação do solo urbano, especialmente naquelas áreas que demandam maior atenção, como as Zonas Especiais de Interesse Social (ZEIS), especificamente no capitulo III, artigo 42-B: “ $V$ - a previsão de áreas para habitação de interesse social por meio da demarcação de zonas especiais de interesse social e de outros instrumentos de política urbana, quando o uso habitacional for permitido;"

Estas áreas possuem especificações urbanísticas de padrões de ocupação próprios, com delimitações de diretrizes para, por exemplo, áreas de favelas, loteamentos e áreas vazias que carecem de urbanização. Aplicável ainda a imóveis subutilizados em áreas dotadas de infraestrutura urbana, na maioria dos casos em áreas centrais das cidades, visando sempre o bem-estar comum e melhor aproveitamento da estrutura urbana posta pelo poder público.

Sobre esta questão Derani (1997) escreve:

A função social da propriedade é baseada na noção que vai contra a lógica da individualidade sustentada pela propriedade privada. Segundo Figueiredo (2008) a concepção nasceu da ideia de que, enquanto parte de uma sociedade, o homem deve empregar esforços no sentido de dar sua contribuição ao bem-estar da coletividade em detrimento dos interesses unicamente individuais. De todo modo, a propriedade passa a ser vista como instrumento de apoio à consecução dos fins sociais, cuja essência é o seu serviço à coletividade (DERANI, 1997, p. 239)

Diante desta breve contextualização pode-se compreender como o processo ocorre no caso de Erechim. Percebe-se que ao ser elaborado o Plano Diretor de Desenvolvimento Urbano e Sustentável de Erechim (PDUSE), houve um cuidado para que não se deixasse de lado a Legislação Federal conforme trecho do Capítulo VI, que fala acerca dos Instrumentos Legais para o Ordenamento Territorial, especificamente no Artigo 70, Inciso I, Letra C: "imposto predial e territorial urbano progressivo, respectivamente, para lotes baldios, construções irregulares ou áreas loteadas em desacordo com as disposições legais" (ERECHIM, 2012). Nota-se que houve um cuidado com os dispositivos legais até então firmados, mas ainda se questiona sua eficiência para se implementar o que já havia sido previsto em legislações anteriores.

Desta maneira, as ZEIS podem ser uma alternativa do Poder Público para a locação de imóveis de cunho habitacional, especialmente os designados para o Programa 'Minha Casa, Minha para Vida' (PMCMV). Este programa foi anunciado em 2009 pelo Governo Federal com o discurso de financiamento da casa própria, destinado a suprir a falta de moradias populares. O programa resume-se a um financiamento privado, através da Caixa Econômica Federal, que contempla duas faixas de renda. A Faixa I para famílias com renda bruta mensal de até R $\$ 1.500$ e a Faixa II compreendendo famílias com renda bruta mensal até $\mathrm{R}$ \$3.600. Ressalta-se que neste artigo não se avalia se esta é uma solução adequada do 
ponto de vista econômico, mas sim seus impactos no desenvolvimento urbano da cidade. Asssim, ao considerar-se algumas características do PMVMC, é possível identificar alguns problemas, conforme indica Rolnik (2014):

É um programa cujo modelo é basicamente construção de casinha e predinho na periferia. A forma como ele é estruturado leva a isso. É muito difícil trabalhar com esse programa para fazer reforma de edifício em área central, e é mais difícil ainda garantir habitação para baixa renda em área central.

É interessante observar a abordagem de Rolnik sobre a forma como o programa se consolida, adotado pelo Poder Público sem considerar a realidade local. A maioria das pessoas que recebem o financiamento através do PMCMV necessitam comprar seus terrenos na periferia, pois o valor financiado não permite que elas adquiram terrenos próximos ao centro e, por fim, resulta a "construção de casinha e predinho na periferia".

Outro fator que deve ser considerado é que o direito à moradia não significa necessariamente o direito a ter uma casa própria. Muitos países europeus, como Alemanha e Itália, trabalham com um sistema de locação social. Pode-se analisar de que forma ele ocorre conforme o Centro Gaspar Garcia de Direitos Humanos - GGDH (2012, p. 21):

A alternativa de moradia aos moldes da locação social nasceu da iniciativa dos Estados de enfrentar o problema da habitação precária que se agravava devido ao crescimento populacional das cidades, provocado pela industrialização. Surge como forma de assegurar aos trabalhadores pobres acesso à moradia adequada, com proximidade ao local do trabalho e a baixos custos de aluguel.

Para que alternativas como o sistema de locação social sejam adotadas, atribuise ao Poder Público Municipal o poder de intervenção para o mapeamento de imóveis desocupados para que se possa analisar se esta seria ou não uma das alternativas para os Municípios suprir a carência de habitação. Ainda segundo GGDH (2012), este modelo não é adotado no Brasil, basicamente devido a três fatores - ao histórico da propriedade imobiliária como forma de renda; à insegurança em relação à previdência social, transformando a propriedade de moradia em garantia de capital; e pela ideologia da casa própria como afirmação de sucesso individual, reforçada no período do regime militar.

Outra questão importante a ser relatada é o custo da cidade periférica, já que os centros das cidades em geral são os locais com-infraestrutura consolidada. No entanto conduzir a expansão do tecido urbano em direção à periferia é aumentar o custo da cidade, pois deixa-se de lado uma infraestrutura pronta, com transporte público, área de lazer, escolas, etc., para uma região que até então encontrava-se desocupada, muitas vezes em áreas agrícolas, distante do centro consolidado, e que requer tempo para alcançar a infraestrutura da área central, acabando por ser subutilizada (WRI BRASIL, 2017). 


\section{METODOLOGIA}

Tomando como base o referencial teórico, foi possível analisar e refletir sobre as políticas de HIS adotadas em Erechim. Estas análises foram feitas principalmente a partir dos dados coletados na Secretaria Municipal de Obras Públicas e Habitação, no Departamento de Habitação da Prefeitura de Erechim, através de entrevistas assistemáticas com os profissionais que lá atuavam em 2014. Através destas informações foi possível fazer um levantamento acerca das políticas públicas direcionadas para atender às demandas de habitação de interesse social, a partir do lançamento do PMCMV em 2009.

As entrevistas ocorreram em fluxo contínuo e diário, assistemáticas, durante o processo de participação de um acadêmico do Curso de Arquitetura e Urbanismo em estágio da Secretaria de Obras Públicas e Habitação da PME, de outubro a dezembro de 2014. Elas foram conduzidas conforme surgiam dúvidas sobre os processos de seleção para os novos loteamentos de Interesse Social, de maneira informal, inquirindo os técnicos sobre como tratavam esta questão, sobretudo em relação às etapas de triagem das famílias, localização dos loteamentos, aquisição dos terrenos, elaboração dos projetos, e dos processos internos de aprovação que ocorriam dentro do departamento. Os dados obtidos foram analisados a partir do referencial teórico para avaliar a efetividade da apliacação destas políticas públicas para solucionar o déficit de habitação em cidades de porte médio, exemplificada pelo caso de Erechim.

\section{RESULTADOS}

O município de Erechim, assim como muitos outros no país, possui problemas em relação à habitação social. Segundo o Departamento de Habitação, estimava-se que o déficit na cidade, em 2014, girava em torno de 2.300 famílias. É importante salientar que este número poderia (e pode ainda hoje) ser maior, pois esses dados foram contabilizados apenas a partir das famílias que se dirigem até à Secretaria durante o processo de triagem realizado para a locação dessas famílias através do PMCMV. Este processo é realizado presencialmente, para se avaliar o seu enquadramento nos requisitos exigidos pelo programa.

O Município estrutura o processo da seguinte forma: primeiramente o públicoalvo, ou seja, as pessoas que têm interesse na moraria, dirigem-se a Prefeitura Municipal e passam por um processo de triagem feito através da avaliação dos candidatos para verificar seu enquadramento no perfil do PMCMV, relativo as faixas de renda I e II. Em seguida ocorrem os sorteios e definem-se quais famílias terão acesso aos lotes que serão vendidos para os sorteados, geralmente localizados em novos loteamentos na periferia da cidade. Quando finalizada esta parte, construtoras são contratadas a partir do processo de licitação para que as edificações sejam construídas e entregues aos novos moradores. $\mathrm{O}$ dever do morador é repassar o financiamento obtido para as construtoras que, com apoio da Prefeitura, realizam o processo de forma geral. 
Após esta etapa inicial a Prefeitura, para facilitar e agilizar o processo de execução do novo empreendimento, faz a aprovação dos empreendimentos, praticamente sem custos, muitas vezes flexibilizando aspectos da legislação para adaptá-las ao modelo do PMCMV e permitir a construção dos empreendimentos em localizações nem sempre previstas no zoneamento de planos diretores, consequentemente, ampliando a malha urbana fora do perímetro urbano.

Uma observação importante é de que a Faixa I, que mais possui demanda, geralmente não chega a ser atendida, pois a parceria entre moradores, prefeitura e construtoras nem sempre se consolida, principalmente pela "falta de interesse das Construtoras relacionado ao lucro ser menor comparado aos atendidos na Faixa II", conforme relatado pelo corpo técnico da Secretaria de Obras Públicas e Habitação.

Outro ponto a ressaltar é que após a conclusão do processo, as famílias atendidas recebem residências antes da infraestrutura estar consolidada. Acaba-se criando assim mais zonas segregadas na cidade, muitas vezes sem as mínimas condições de urbanidade. Em muitos casos as áreas não são servidas pelo transporte público, não possuem nenhum tipo de serviço próximo, como Unidades Básicas de Saúde, Creches, Escolas, entre outros, tais como os Correios, que frequentemente não prestam serviço nestas áreas.

Este estudo não se detém em analisar como a individualidade dos interessados no programa é considerada no projeto proposto, pressupondo que cada família tem suas necessidades específicas, gostos, costumes e comportamentos que as identificam enquanto indivíduos únicos, e que isto impacta também as tipologias arquitetônicas. Vimos que nesses casos esse fator é desconsiderado pelas construtoras na elaboração dos projetos arquitetônicos das residências. Geralmente, neste modelo de implantação é definido um projeto padrão, que é cotidianamente conhecido como "loteamento carimbo", onde inúmeras residências exatamente iguais são replicadas nos loteamentos, dominando e uniformizando a paisagem das periferias (Fig. 2).

Figura 2: Modelo de loteamento HIS em Erechim, RS.

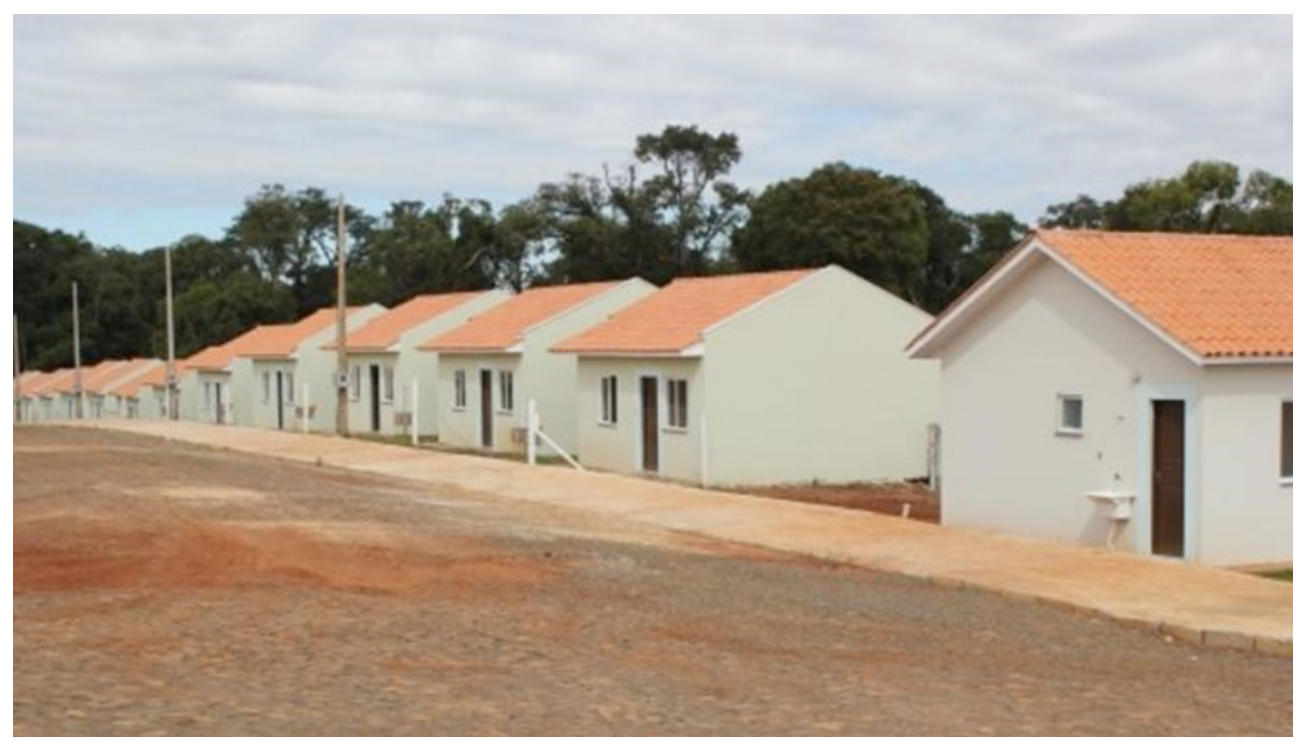

Fonte: Prefeitura Municipal de Erechim, 2014 
Além de desconsiderar a individualidades dos novos moradores, não são avaliadas as condições do sítio físico, tais como topografia, drenagem e insolação, técnicas construtivas ou até mesmo as características regionais na implementação desses novos loteamentos.

Apesar disto, algumas iniciativas surgiram a partir da parceria entre a Prefeitura Municipal de Erechim e o Curso de Arquitetura e Urbanismo da Universidade Federal da Fronteira Sul (UFFS) buscaram melhorar os aspectos citados. Através desta parceria, alguns acadêmicos do Curso têm trabalhado para ajustar os novos loteamentos, auxiliando na implantação do conjunto e dos edifícios arquitetônicos. Dentre tais medidas, algumas edificações foram adaptadas para serem acessíveis, como também os projetos foram mais bem detalhados a fim de facilitar o processo construtivo das edificações. Todavia, essas iniciativas foram pequenas, pontuais e limitadas com relação à problemática geral.

Em Erechim os empreendimentos do PMCMV se concentram na periferia, totalizando em 12 loteamentos localizados a noroeste e no sul do município (Fig. 3), com justificativas embasadas no menor valor dos terrenos. Todavia, lembra-se que o valor da terra é controlado pelo Poder Público Municipal, através do zoneamento do Plano Diretor, o qual indica os possíveis usos e ocupação para o solo urbano, variável em cada parte da cidade, e que seus donos não detem poder absoluto sobre os terrenos.

Figura 3. Loteamentos no município de Erechim, RS.

\section{ERECHIM: LOTEAMENTOS DE INICIATIVA PARTICULAR E DA PREFEITURA MUNICIPAL (1956-2011)}

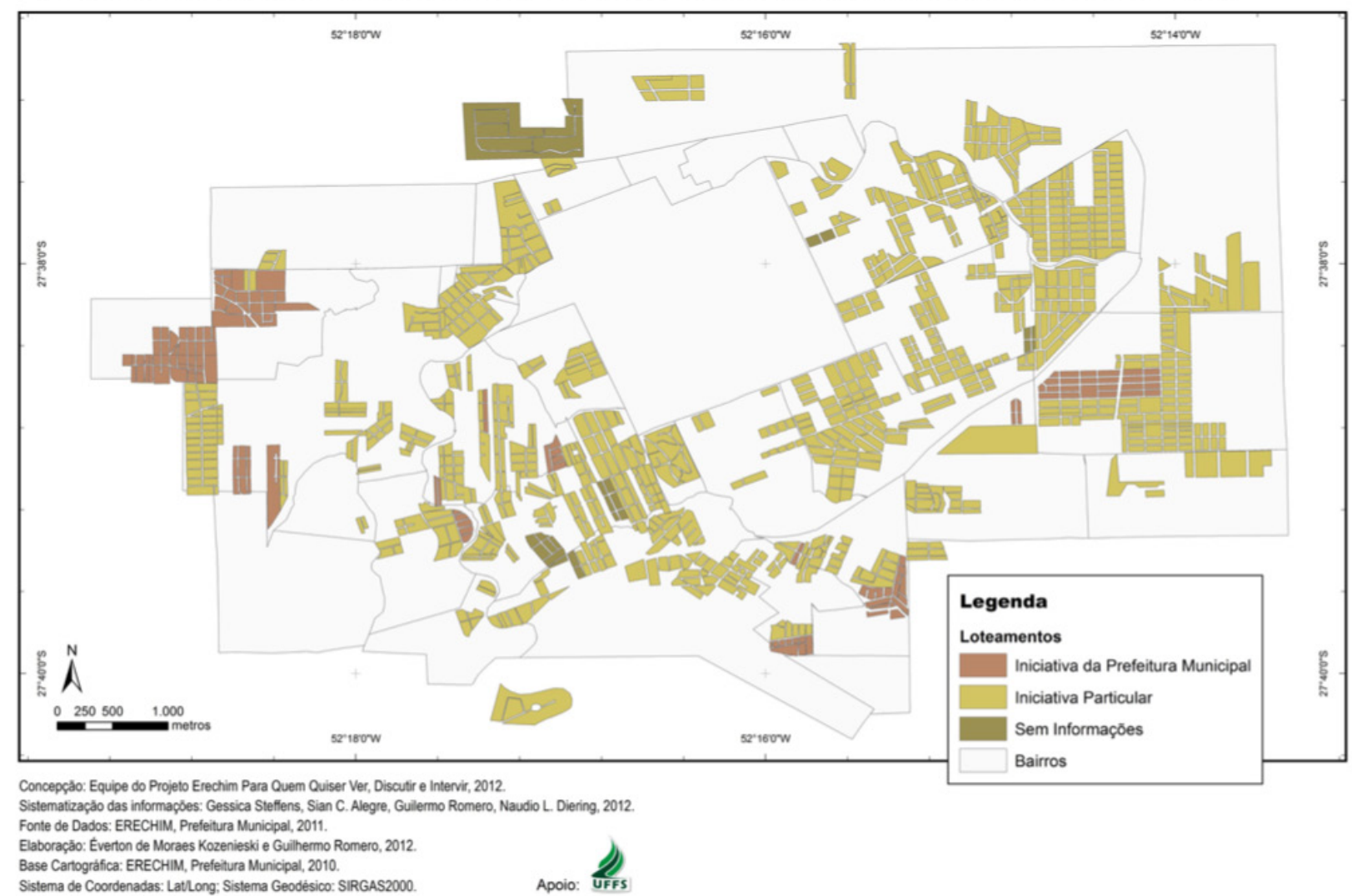

Fonte: IBGE, 2010; ERECHIM para quem quiser ver, discutir e intervir (2012) 
Outro fator desfavorável aos demais modelos de moradia é também devido a não se encontrar nenhuma especificação, tais como prazos, que determine como os instrumentos previstos no Estatuto da Cidade, como a Desapropriação com Pagamento de Títulos, possam efetivamente ser implementados. O único instrumento verificado, o IPTU Progressivo, isoladamente não é efetivo para arbitrar outros modelos de para a efetivação da legislação vigente.

No caso de Erechim, não se tem relatos deste controle. Tanto que se percebe que, na prática, todos os loteamentos destinados à HIS localizam-se na periferia da cidade, com a justificativa de que pelo valor do financiamento é apenas naquelas regiões ser possível encontrar lotes com valores compatíveis com o orçamento previsto pelo PMCMV.

Outra questão analisada é a de que muitos desses novos loteamentos se resumem a casas, em geral térreas, e em poucos casos se verifica uma ocupação de forma verticalizada.

Segundo Bonduki (1995, p. 90), “Os gigantescos núcleos, constituídos por filas intermináveis de casas, obrigam à criação de oneroso e complexo sistema de transporte e comunicações, exigindo encargos vultosos no estabelecimento e manutenção dos serviços de utilidades públicas em geral."

Além disso, nem sempre os serviços públicos tornam-se parte da vida dos cidadãos dos loteamentos periféricos, devido ao custo de se implantar a nova infraestrutura.

\section{CONCLUSÃO}

A efetivação do PMCMV em Erechim constitui uma situação comum a diversas cidades do interior. Entretanto, o que é alarmante nesta situação é a replicação de problemas comuns, que já tinham sido revelados nas grandes cidades, e agora presentes nas cidades de porte médio, sem um planejamento apreendido dos casos anteriores, nas metrópoles.

Diante desta problemática abordada, verifica-se que outras soluções poderiam ter sido adotadas como medidas para abater o déficit habitacional da cidade, bem como a ausência de políticas preventivas para que tal problemática não continuasse a ocorrer. A ocupação dos vazios urbanos na cidade, ou mesmo o 'aluguel social', já implementados em diversos países europeus, poderiam constituir algumas das soluções a serem analisadas e adaptadas à realidade das cidades médias brasileiras.

Percebe-se que enquanto a ocupação de casas térreas isoladas no lote gera os problemas já relatados, sugere-se outras soluções, como a ocupação vertical. Algumas obras, como alguns conjuntos habitacionais construídos na época do Instituto de Aposentadorias e Pensões dos Industriários (IAPI) e que hoje são um exemplo mais adequado de ocupação, também de caráter vertical, podiam ter sido estruturadas e replicadas em situações como as do PMCMV. Entretanto, salienta-se a importância de estar atento aos detalhes do projeto dos loteamentos, pois parte dessas obras já previa, além dos edifícios residenciais, as escolas, espaços livres e equipamentos públicos, o que faria toda a diferença nessas ocupações, criando espaços urbanos com infraestrutura e, consequentemente, urbanidade. Além disso, outra proposta não levada em consideração seria a catalogação de imóveis vazios 
para fins de reutilização. Para isso seria ainda necessário um programa habitacional que fizesse a gestão e organizasse as novas unidades para um novo uso, readequando-as para cumprir sua Função Social. Isto contribuiria diretamente para que a cidade crescesse de forma mais equilibrada e não fossem necessárias as novas ocupações em áreas afastadas e sem infraestrutura.

Desta maneira, pode-se concluir que não se justifica a criação de novos loteamentos nas periferias quando ainda restam vazios urbanos ou imóveis desocupados que poderiam ser readequados, uma vez que o custo de infraestrutura sobrecarrega o Estado, além de que este pode fazer uso dos instrumentos previstos no Estatuto da Cidade para que se faça o Uso Social da Propriedade, garantindo cidades mais homogêneas, compactas e com crescimento planejado e sustentável.

Estas medidas citadas podem ser efetivadas se adaptadas ao contexto das cidades de médio porte como-já vem sendo aplicadas em outros contextos urbanos, como nas metrópoles. Acredita-se que, se bem estudados e readaptadas para este contexto, podem servir como base para um planejamento urbano mais sustentável também para o caso das cidades de médio porte brasileiras.

\section{REFERÊNCIAS}

BONDUKI, Nabil. Origens da Habitação Social no Brasil: arquitetura moderna, lei do inquilinato e difusão da casa própria. 4.ed. São Paulo: Estação da Liberdade, 2004.

BRASIL. Constituição da República Federativa do Brasil. 1988. Disponível em: http:/ / www.planalto.gov. br/ccivil_03/Constituicao. Acesso em: 25 ago. 2018.

BRASIL. Estatuto da Cidade: Lei 10.257/2001 que estabelece diretrizes gerais da política urbana. Brasília, 2001.

DERANI, Cristiane. Direito Ambiental Econômico. São Paulo: Max Limonad, 1997.

ERECHIM, Prefeitura Municipal. 2012. Plano Diretor de Desenvolvimento Urbano e Sustentável de Erechim.

ERECHIM para quem quiser ver, discutir e intervir: democratizando o acesso às informações socioambientais da cidade. Caderno de mapas de Erechim. Erechim: UFFS, 2012. (Projeto de Extensão).

GGDH - Centro Gaspar Garcia de Direitos Humanos. Moradia é central: lutas, desafios e estratégias. São Paulo, 2012. Disponível em: http://gaspargarcia.org.br/documento/moradia-e-central-lutas-desafios-eestrategias-2012/ Acesso em: 23 set. 2019.

HOLANDA, Anna Carolina Gomes. A nova Política de Habitação de Interesse Social no Pará (20072010): avanços e limites. Belém, 2011. Dissertação (Mestrado em Desenvolvimento Sustentável do Trópico Úmido) - Universidade Federal do Pará, UFPA.

IBGE - Instituto Brasileiro de Geografia e Estatística. Região de Influencia das Cidades. Rio de Janeiro, 2007.

IBGE - Instituto Brasileiro de Geografia e Estatística. Censo Demográfico 2010. Rio de Janeiro, 2010. Disponível em: http:/ / censo2010.ibge.gov.br. Acesso em: 15 dez. 2018.

ROLNIK, Raquel. Vivemos uma emergência habitacional em São Paulo. São Paulo, 2014. Disponível em: https:// raquelrolnik.wordpress.com/2014/11/28/vivemos-uma-emergencia-habitacional-em-saopaulo/ Acesso em: 12 dez. 2014. 
WRI BRASIL. Caderno 1: Análise de Custos Referenciais: qualificação da inserção urbana. Brasília: Ministério das Cidades, 2017. Disponível em: https://wribrasil.org.br/sites/default/files/MCMV_ Caderno1_jan2018.pdf Acesso em: 23 set. 2019.

Data de submissão: 28/fev./2019

Data de aceite: 29/ago./2019 